\title{
Resourcing issues
}

Juan José Gagliardino

CENEXA (Centre of Experimental and Applied Endocrinology), National University of La Plata - National Research Council (PAHO/WHO Collaborating Centre in Diabetes), School of Medicine, La Plata University, Calles 60 y 120, 1900 La Plata, Argentina

(Correspondence should be addressed to J J Gagliardino; Email: cenexa@speedy.com.ar)

\begin{abstract}
Diabetes is a chronic, progressive disease and achieving appropriate control of glycaemia and the other associated cardiovascular risk factors is essential to prevent its long-term complications. Currently, recovery and rehabilitation from the cardiovascular complications of diabetes are the major focus of diabetes care rather than primary and secondary prevention of diabetes and its complications. This focus, coupled with limited funding and other resource issues, means that diabetes care and outcomes are generally suboptimal. More efficient and effective management strategies, primarily based upon a broad educational approach including both those with diabetes and their care-givers will be essential in reducing the cost of diabetes and diabetes-related complications. Continuous education of patients and providers increases the quality of care and improves clinical and metabolic outcomes as well as reducing the cost of care and optimising human and financial resources. Thus, education will be a key strategy in minimising the growing burden of diabetes on society. Making these changes will require the co-operation of patients, their families, the community, healthcare policy makers, national governments and the pharmaceutical industry. Medical schools must also place more emphasis on educating doctors about chronic disease management using not only recovery and rehabilitation, but also prevention strategies, emphasising the importance of helping patients to participate in the control of their disease.
\end{abstract}

European Journal of Endocrinology 151 T9-T11

\section{Introduction}

Diabetes mellitus is a common and costly health problem with chronic complications resulting in a heavy socio-economic burden $(1,2)$. The prevalence of diabetes, particularly type 2 diabetes, is increasing rapidly throughout the world (3). The development and progression of chronic cardiovascular complications are the major cause of the morbidity, mortality and costs of diabetes (3). These complications can be significantly reduced by controlling blood glucose levels and managing cardiovascular risk factors. Even relatively small changes in these parameters can result in significant decreases in the incidence and progression of diabetes-related complications $(4,5)$.

An economic model based on Diabetes Control and Complications Trial (DCCT) and United Kingdom Prospective Diabetes Study (UKPDS) outcomes suggests that intensive life-long treatment strategies are relatively cost-effective, with a cost per quality-adjusted life-year gained of about US \$16000, well within the range of most accepted preventative strategies (6). The Centre for Disease control examined the relative costs of treating hyperglycaemia, hypertension and hyperlipidaemia and concluded that these costs are within the acceptable range for preventative interventions (7). However, the effectiveness of prevention strategies has not been widely realised in clinical practice $(8)$ and, unfortunately, the care received by people with diabetes is frequently far from optimal both in developed and developing countries $(9,10)$. We have also shown that between 20 and $30 \%$ of patients with diabetes either do not receive or do not follow systematic control and treatment programmes (11). Consequently, the percentage of people with diabetes that present micro- and macrovascular complications increases as a function of the poor metabolic control and the duration of diabetes (Table 1) (10). Therefore, unless we invest in effective strategies to improve metabolic control now, we will be faced with the need to dramatically increase healthcare budgets in the future in order to cope with the increased burden of diabetes-related complications as the disease progresses in this population.

\section{Factors affecting quality of care}

The quality of diabetes care is determined by numerous factors including the accessibility of care, drugs, and devices, the knowledge, skills and experience of the healthcare team, and the active participation of patients in the control and treatment of their disease (patient empowerment). Maximising each of these 
Table 1 Frequency of chronic complications according to type 2 diabetes duration. Figures represent average percentage values, $n=13513$.

\begin{tabular}{lcccc}
\hline & \multicolumn{4}{c}{ Duration of diabetes (years) } \\
\cline { 2 - 5 } & $0-5$ & $6-10$ & $11-20$ & $>20$ \\
\hline Retinopathy & 10 & 20 & 38 & 48 \\
Blindness & 1.7 & 2.8 & 3.2 & 6.7 \\
Peripheral neuropathy & 21 & 29 & 37 & 42 \\
ESRD & 0.2 & 0.4 & 0.7 & 1.5 \\
AMI & 1.5 & 1.8 & 4.3 & 6.7 \\
CVA & 2.1 & 3.5 & 2.9 & 3.3 \\
Amputations & 1.0 & 1.4 & 3.6 & 7.3 \\
\hline
\end{tabular}

$\mathrm{Chi}^{2}$ for trends $P<0.001$.

ESRD, end-stage renal disease; AMI, acute myocardial infarction; CVA, cerebrovascular accident.

(Taken from Gagliardino et al. (10))

components will improve diabetes prevention, decrease the incidence of diabetes-related complications, and improve the quality of life for patients with diabetes. Processes and outcomes should continuously be evaluated so that intervention strategies can be adapted to optimise outcomes and the utilisation of resources (see model shown in Fig. 1). Education is either explicitly or implicitly included in each one of the model's components.

Although insufficient financial resources can significantly impair access to diabetes care, Grandjour et al. have reported that the level of investment is not closely related to the quality of care (12). Furthermore, whilst a certain level of funding is critical, education can enhance the quality of care even if resources are scarce. Unfortunately, the importance of diabetes health education is often underestimated. Karter et al. (8) showed that even when all diabetes care services were offered free of charge, the probability of patients receiving health education was low compared with other interventions such as annual dilated eye examinations or daily self-monitoring of blood glucose.
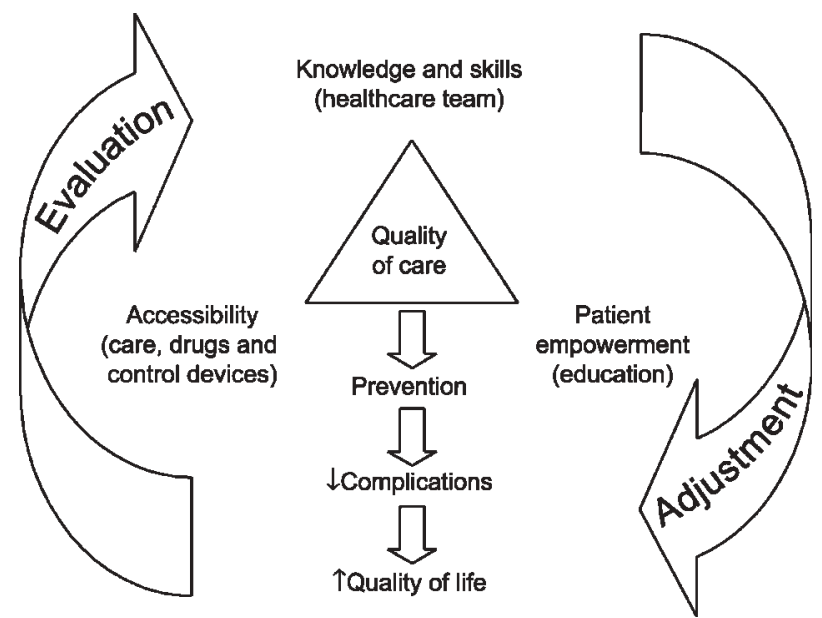

Figure 1 Model for improving quality of diabetes care.

\section{Optimising resource utilisation}

Many studies support the rationale for providing both patient and professional education to improve the quality of diabetes care and to optimise the use of healthcare resources. The implementation of the Training Program for General Practitioners (PROCAMEG) in Argentina significantly improved clinical and biochemical parameters in the attending practitioners' patients after 1 year (Table 2) (13). In addition, a multicentre study carried out in 10 Latin American countries showed that intensive educational courses for people with diabetes resulted in significantly improved clinical, metabolic and economic parameters (PEDNID-LA) (14). Finally, a comprehensive, integrated programme that included both physician and patient education (Program of Prevention, Care and Treatment of People with Diabetes (PROPAT)), within a managed care organisation in Buenos Aires (Instituto de Obra Médico Asistencial (IOMA)) was associated with improvements in several clinical and biochemical parameters after 1 year, and a $28 \%$ decrease in the total annual per capita costs (15).

Educational interventions have also been shown to be effective for the primary prevention of type 2 diabetes in populations with impaired glucose tolerance (16-18). Thus, investing in the development of more efficient and cost-effective diabetes prevention and management strategies via patient education will be a key strategy in curbing the accumulating cost of treating diabetes-related complications.

\section{Conclusions}

Diabetes is a chronic, progressive disease. Achieving appropriate levels of glycaemic control and managing cardiovascular risk factors in order to prevent longterm diabetes-related complications poses numerous challenges both to patients and their healthcare providers. Complicated by an ongoing progression of type 2 diabetes due to a decline in beta-cell function, treatment goals are frequently not met in clinical practice.

Table 2 Clinical and metabolic changes in patients with type 2 diabetes before and after a 1-year diabetes practitioner training programme.

\begin{tabular}{lcc}
\hline & Before & After \\
\hline Body weight $(\mathrm{kg})$ & $79 \pm 14$ & $75 \pm 13$ \\
Body mass index $\left(\mathrm{kg} / \mathrm{m}^{2}\right)$ & $29 \pm 5$ & $27 \pm 5$ \\
Systolic blood pressure $(\mathrm{mmHg})$ & $144 \pm 22$ & $124 \pm 23$ \\
Diastolic blood pressure $(\mathrm{mmHg})$ & $96 \pm 22$ & $80 \pm 9$ \\
Fasting blood glucose & $210 \pm 71$ & $150 \pm 40$ \\
HbA $_{1 \mathrm{c}}$ & $9.8 \pm 2$ & $7.8 \pm 1$ \\
Total cholesterol $(\mathrm{mg} / \mathrm{dl})$ & $239 \pm 79$ & $207 \pm 28$ \\
Triglycerides $(\mathrm{mg} / \mathrm{dl})$ & $215 \pm 92$ & $165 \pm 51$ \\
\hline
\end{tabular}

$P<0.001$ for difference.

Reprinted with permission from (13). 
Traditionally, the major focus of diabetes care has been the treatment of diabetes-related cardiovascular complications, rather than the primary and secondary prevention of the disease. This focus, coupled with limited funding and other resource issues, means that diabetes care is generally suboptimal.

A greater investment in the primary and secondary prevention of diabetes and its complications, together with more efficient and effective management strategies based largely on patient/practitioner education will be essential for reducing the future costs of diabetes healthcare. However, there is likely to be a threshold level of financial investment, below which outcomes do not improve or deteriorate, and above which there is no additional improvement. Despite this, continuously educating patients and healthcare providers increases the quality of care, improves clinical and metabolic outcomes, lowers care costs, and contributes to the optimisation of human and financial resources, irrespective of resource availability. Thus, education will be a key strategy for minimising the growing burden of diabetes to society.

Optimising diabetes care will require the co-operation of patients, their families, the community, healthcare policy makers, national governments and the pharmaceutical industry. In addition, medical schools must place more emphasis on educating doctors about chronic disease management using not only recovery and rehabilitation strategies but also preventative strategies, emphasising the importance of the patients' role in the management of their own disease. An urgent response is required from all those concerned with improving the quality of diabetes care before the opportunity is missed.

\section{References}

1 Jonsson B. The economic impact of diabetes. Diabetes Care 1998 21 (Suppl) C7-C10.

2 Williams R, Van Gaal L \& Lucioni C. Assessing the impact of complications on the costs of type II diabetes. Diabetologia $2002 \mathbf{4 5}$ S13-S17.

3 King H, Aubert RE \& Herman WH. Global burden of diabetes 1995-2025. Diabetes Care 199821 1414-1431.

4 The Diabetes Control and Complications Trial Research Group, Lifetime benefits and costs of intensive therapy as practices in the diabetes control and complications trial. Journal of the American Medical Association 1996276 1409-1415.

5 Gray A, Raikou M, McGuire A, Fenn P, Stevens R, Cull C, Stratton I, Adler A, Holman R \& Turner R. Cost effectiveness of an intensive blood glucose control policy in patients with type 2 diabetes: economic analysis alongside randomised controlled trial (UKPDS 41). United Kingdom Prospective Diabetes Study Group. British Medical Journal 2000320 1373-1378.

6 Eastman RC, Javitt JC, Herman WH, Dasbach EJ, Copley-Merriman C, Maier W, Dong F \& Manninen D. Model of complications of NIDDM. II. Analysis of the health benefits and cost-effectiveness of treating NIDDM with the goal of normoglycemia. Diabetes Care $199720735-744$.

7 The CDC Diabetes Cost-effectiveness Group. Cost-effectiveness of intensive glycemic control, intensified hypertension control, and serum cholesterol level reduction for type 2 diabetes. Journal of the American Medical Association $20022872542-2551$.

8 Karter AJ, Stevens MR, Herman WH, Ettner S, Marrero DG, Safford MM, Engelgan MM, Curb JD \& Brown AF; Translating Research into Action for Diabetes Study Group. Out-of-pocket costs and diabetes preventive services: the Translating Research Into Action for Diabetes (TRIAD) study. Diabetes Care 200326 2294-2299.

9 Saddine J, Engelagu M, Beckles G, Gregg E \& Thompson T. A diabetes report card for the United States: quality of care in the 1990s. Annals of Internal Medicine 2002136 565-574.

10 Gagliardino JJ, de la Hera M, Siri F \& y Grupo de Investigacion de la Red Qualidiab. Evaluacion de la calidad de la asistencia al paciente diabetico en America Latina. Revista Panamericana de Salud Pública/Pan American Journal of Public Health 200110 309-317 [Article in Spanish and English].

11 Gagliardino J \& Olivera E. The regions and their health care systems: Latin America. In Economics of Diabetes and Diabetes Care. A report of the Diabetes Health Economics Study Group, pp 51-59. Eds W Gruber, T Lander, B Leese, T Songer \& H Williams. Brussels: International Diabetes Federation, 1997.

12 Grandjour A, Kleinschmit F \& Lauterbach KW. INTERCARE International Investigators. European comparison of costs and quality in the prevention of secondary complications in type 2 diabetes mellitus (2000-2001). Diabetic Medicine 200219 594-601.

13 Gagliardino JJ, Jadzinsky M, Alvarinas J, Fabiano A, Sereday M, Sinay I and the PROCAMEG Research Group. Sociedad Argentina de Diabetes. Programa de capacitacion diabetologica para medicos generalistas (PROCAMEG). Revista de la Sociedad Argentina de Diabetes 199832 205-210 [Article in Spanish].

14 Gagliardino J, Etchegoyen G \& the PEDNID-LA Research Group. A model education program for people with type 2 diabetes: a cooperative Latin-American implementation study. Diabetes Care 2001 24 1001-1007.

15 Gagliardino J, Olivera E, Etchegoyen G, Guidi ML, Martella A, Caporale JE, De La Hera M, Siri F and Bonelli P (2001) Control y prevención secundaria para personas con diabetes: impacto de la implementación de un programa de atención (PROPAT). Revista de la Sociedad Argentina de Diabetes 35 77-86 [Article in Spanish].

16 Pan X, Li G, Hu Y-H, Wang JX, Yang WY, An ZX, Hu ZX, Lin J, Xiao JZ, Cao HB, Lui PA, Jiang XG, Jiang YY, Wang JP, Zheng H, Zhang H, Bennett PH \& Howard BV. Effects of diet and exercise in preventing NIDDM in people with impaired glucose tolerance: the Da Qing IGT and Diabetes Study. Diabetes Care 199720 537-544.

17 Diabetes Prevention Program Research Group. Reduction in the incidence of type II diabetes with lifestyle intervention or metformin. New England Journal of Medicine 2002346 393-403.

18 Tuomilehto J, Lindstrom J, Eriksson J, Valle TT, Hamalainen H, Ilanne-Parikka P, Keinanen-Kivkoannlemi S, Laakso M, Louheranta A, Rastas M, Salminen V, Uusitupa M; Finnish Diabetes Prevention Study Group. Prevention of type 2 diabetes mellitus by changes in lifestyle among subjects with impaired glucose tolerance. New England Journal of Medicine $\mathbf{3 4 4} 1343-1350$.

Received 19 May 2004

Accepted 24 May 2004 